\title{
The evolution and preliminary genesis of the carbon isotope for coal measure tight gas: cases from upper paleozoic gas pools of ordos basin and xujiahe formation gas pools of sichuan basin, China
}

\begin{abstract}
In this study, the geochemistry data of 162 coal measure tight gas samples (77) samples from Ordos Basin, 85 samples from Sichuan Basin) is collected. Then, the carbon isotope evolution of coal measure tight sandstone gas is investigated. The result indicates that three features in carbon isotope evolution of coal measure tight gas appear. (1) The coal measure tight gas has a same feature as shale gas, that the carbon isotope of heavy gas would show a rollover with the decreasing wetness of gases. The corresponding range of gas wetness is about $2.5 \% \sim 5 \%$ at which the carbon isotope of ethane begin to rollover. (2) The carbon isotope series of coal measure tight gas presents successively positive sequence, partial reversal and full reversal with increasing maturity of source rock. (3) The maturity ranges corresponding to of coal measure tight gas with the positive sequence, partial reverse and full reverse of carbon isotope are $\mathrm{R}_{0}<2.0 \%, \mathrm{R}=1.75 \sim 3.0 \%$ and $\mathrm{R}>3.0 \%$ of in-situ source rock, respectively. On the bases of pyrolysis experiment of a I type of organic matter, the authors propose that the mixing between primary and cracking gas could just only cause the carbon isotope rollover of heavy hydrocarbon gases, but not cause the carbon isotopic reversal of hydrocarbon. Finally, a conclusion is suggested that carbon isotope reversal of coal measure gas has a close relationship with demethylation happening at the maturity above $3.0 \% \mathrm{R}_{\mathrm{o}}$ according to published data about coal chemical structure measurement. The isotopic fractionation during the process of heavy gases formation by linkage of methyl from demethylation is one of capital factors of carbon isotopic reversal.
\end{abstract}

Volume 2 Issue 8 - 2017

\author{
Jingkui Mi, ${ }^{1,2}$ Guoyi Hu, ${ }^{1,2}$ Jingfang Bai, ${ }^{2}$ \\ Changyue Liu $^{2}$ \\ 'State Key Laboratory for Enhanced Oil Recovery, China \\ ${ }^{2}$ Research Institute of Petroleum Exploration and Development, \\ Petro china
}

\begin{abstract}
Correspondence: Jingkui Mi, State Key Laboratory for Enhanced Oil Recovery, Beijing 100083, China, Tel +86- 010 8359 3053,Email jkmi@petrochina.com.cn
\end{abstract}

Received: September 12, 2017| Published: December 18, 2017

Keywords: coal measure tight gas, carbon isotope evolution, carbon isotopic reversal, maturity of source rock, formation mechanism

\section{Introduction}

In classic theory, the natural gas generated by organic matter $(\mathrm{OM})$ would become dry with the increase of source rock maturity. ${ }^{1}$ Meanwhile, the carbon isotope of gas would become heavy during the evolution process of source rock. ${ }^{2-4}$ However, some new characteristics of geochemistry appear in shale gas found in shale with over maturity, such as the isotopic rollover, partial reversal and full reversal. ${ }^{5-9}$ The isotopic rollover refers to that the isotopic value of one heavy gaseous component $\left(>\mathrm{C}_{2}\right)$ does not become heavy with the decreasing wetness or increasing maturity of source rock, but become light in a certain range of gas wetness. For example, the carbon isotope of ethane from shale gas found in North America increases with its decreasing wetness initially. Then it decreases with the further decreasing wetness of shale gas. ${ }^{7}$ While, the isotopic reversal means that the isotope value do not increase with the increase of carbon number in gas, but become light $\left(\delta^{13} \mathrm{C}_{1}>\delta^{13} \mathrm{C}_{2}>\delta^{13} \mathrm{C}_{3}\right)$.

Hao et al. ${ }^{7}$ proposed there is a close relationship between the carbon isotope distribution of shale gas and the maturity level of source rock (shale). The corresponding maturity ranges at which the isotope rollover, partial isotope reversal and completely isotope reversal of shale gas occurred are about 1.3 1.5\% $\mathrm{R}_{\mathrm{o}}, 1.5 \sim 1.9 \% \mathrm{R}_{\mathrm{o}}$ and much more than $2.0 \% \mathrm{R}_{\mathrm{o}}$, respectively. The corresponding wetness at which $\delta^{13} \mathrm{C}_{2}$ begins to rollover is about $6 \%$ for Barnett shale gas. Although many researchers had been studied the mechanisms and the causes of the isotopic rollover and reversal of shale gases, their origins are not inadequately understood. Some suggested that the isotopic reversal of shale gases at the over-mature stage is caused by the mixing of both kerogen cracking and secondary cracking of retained hydrocarbons..$^{5,8,10}$ Others proposed that the redox reaction between water and methane generated isotopically light carbon dioxide and hydrogen at geological temperatures of $250-300^{\circ} \mathrm{C}\left(5.0 \% \mathrm{R}_{\mathrm{o}}\right)$, further reaction between carbon dioxide and hydrogen formed isotopically light ethane. ${ }^{6,11}$ In last few years, the isotopic reversal was observed in coal measure tight gas whose reservoir closes to its source rock of coal bearing formation and maturity of source rock arrives over maturity level. ${ }^{12,13}$ Thus, the isotopic reversal is common characteristic for natural gas no matter from shale or coal bearing formation with over maturity. Meanwhile, a question arises whether the isotope of coal measure tight gas has a similar evolution trend as shale gas with increasing maturity of source rock or decreasing wetness of gas. This is very significant to interpret the isotopic reversal mechanisms and further unravel the mechanism of gas generation from the source rock at over maturity stage.

In this study, the geochemistry of 155 coal derived gas samples from Xujiahe formation of Sichuan basin (88) and Upper Paleozoic of Ordos basin (67), west-central China is collected Figure 1. The objective of this study is to clear the carbon isotope evolution of coal measure tight gas and to probe preliminarily the isotopic reversal mechanisms of natural gas generated at over maturity stage. 


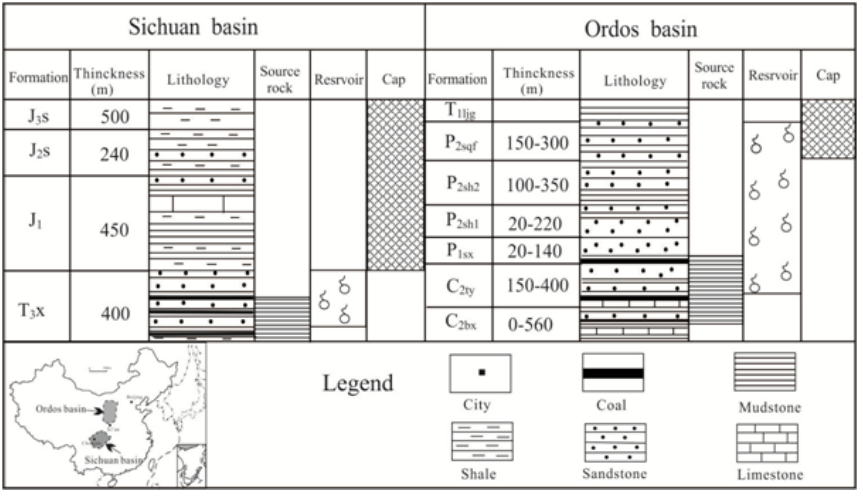

Figure I The assemblage of source rock, reservoir and cap for gas fields found in Xujiahe (T) group of Sichuan basin and in Upper Paleozoic (C-P) of Ordos basin.

\section{Background}

Sichuan and Ordos basins are located in the west-central China (Figure 1). The Xujiahe group (T) and Upper Paleozoic (C-P) are chief coal bearing formations in Sichuan and Ordos basins, respectively. The Xujiahe group in Sichuan basin is divided into six segments $\left(\mathrm{T}_{3 \mathrm{X}}{ }^{1} \sim \mathrm{T}_{3 \mathrm{X}}{ }^{6}\right)$. The lithology of $\mathrm{T}_{3 \mathrm{X}}{ }^{1}, \mathrm{~T}_{3 \mathrm{x}}{ }^{3}$ and $\mathrm{T}_{3 \mathrm{X}}{ }^{5}$ is mainly mudstone, shale, carbon shale and coal interbedded with thin sandstone, which is the main source rock. The lithology of $\mathrm{T}_{3 \mathrm{X}}{ }^{2}, \mathrm{~T}_{3 \mathrm{X}}{ }^{4}$ and $\mathrm{T}_{3 \mathrm{X}}{ }^{6}$ is tight sandstone chiefly, which is the reservoir of coal measure gas. The source rock of Xujiahe group shares a relatively low maturity and its range is $0.5 \sim 2.0 \% \mathrm{R}_{0}{ }^{14}$ The tight sandstone of gas reservoir in Upper Paleozoic of Ordos basin is developed in Permian chiefly. The cover layer of gas reservoir is the mudstone of Upper Shihezi group developed in Permian. The maturity of C-P source rock is high and arrives to $1.0 \sim 3.2 \% \mathrm{R} .{ }^{14}$ Previous work had proved that the gas found in Xujiahe group of Sichuan basin and the Upper Paleozoic of Ordos basin is coal derived gas. ${ }^{14,15}$ Thus, the maturity range $\left(\mathrm{R}_{\mathrm{o}}=0.5 \sim 3.2 \%\right)$ of source rock selected from the two basins in this study is wide enough to unravel the isotopic evolution of coal measure tight gas with increasing maturity of source rock.

\section{The carbon isotopic evolution of coal derived tight gas}

\section{The carbon isotopic evolution with decreasing wetness of gas}

The conventional theory of gas generation suggests that the higher of source maturity, the less of wetness for gas generated by one type of $\mathrm{OM}$ is. Thus, the wetness of natural gas is often taken as a parameter to scale the maturity of its source rock. The carbon isotopic evolution of methane and ethane from the two basins with decreasing wetness is present in Figure 2. There are three similar features in evolution of $\delta^{13} \mathrm{C}_{1}$ and $\delta^{13} \mathrm{C}_{2}$ with decreasing wetness for the coal gas from the two basins. (1) $\delta^{13} \mathrm{C}_{1}$ value becomes heavy with decreasing wetness of the gas. (2) A rollover feature in $\delta^{13} \mathrm{C}_{2}$ is displayed with decreasing wetness of the gas. (3) The rollover threshold of $\delta^{13} \mathrm{C}_{2}$ is about $-20 \%$; Meanwhile, two different evolution features in carbon isotope with decreasing wetness of the gas could also be observed. (1) The rollover degree of $\delta^{13} \mathrm{C}_{2}$ of gas $(-20 \%$ -39\%) from Ordos basin is higher than that of gas $(-20 \%$ $-30 \%$ ) from Sichuan basin. (2) The value of wetness which corresponds to the turning point of $\delta^{13} \mathrm{C}_{2}$ rollover is different for the gas from two basins. The wetness corresponding to the turning point of $\delta^{13} \mathrm{C}_{2}$ rollover for the gases from Sichuan and Ordos basin is about $2.5 \%$ and $5 \%$, respectively.
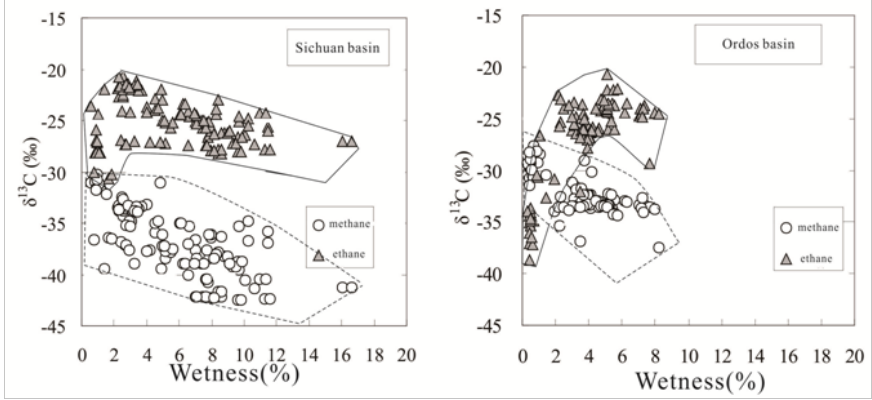

Figure 2 The $\delta^{13} C_{1}$ and $\delta^{13} C_{2}$ evolution with decreasing wetness of gas.

\section{The carbon isotope relationships among of different hydrocarbon components}

The carbon isotope relationships among of different hydrocarbon components are presented in Figure 3. In overall, a wide " $\mathrm{V}$ " shape relationship between $\delta^{13} \mathrm{C}_{1}$ and $\delta^{13} \mathrm{C}_{2}$ could be observed (Figure 3a). $\delta^{13} \mathrm{C}_{2}$ becomes heavy with increasing $\delta^{13} \mathrm{C}_{1}$ initially. Then it becomes light with increasing $\delta^{13} \mathrm{C}_{1}$ at the point of $\delta^{13} \mathrm{C}_{2}=-20 \%$. Finally, the reversal between $\delta^{13} \mathrm{C}_{1}$ and $\delta^{13} \mathrm{C}_{2}$ appears (below the line of $\delta^{13} \mathrm{C}_{1}=\delta^{13} \mathrm{C}_{2}$ ). Most gas samples from Sichuan basin sharing relatively low maturity of source rock are located in the left area of "V" shape. Although some gas samples from Sichuan basin are located in the right area of "V" shape, all the samples from Sichuan basin present a normal series distribution between $\delta^{13} \mathrm{C}_{1}$ and $\delta^{13} \mathrm{C}_{2}\left(\delta^{13} \mathrm{C}_{1}<\delta^{13} \mathrm{C}_{2}\right)$. All the gas samples from Ordos basin bearing high maturity of source rock are located in the right area of " $\mathrm{V}$ " shape. There is a rough decreasing trend in $\delta^{13} \mathrm{C}_{2}$ with increasing $\delta^{13} \mathrm{C}_{1}$ of the gas samples from Ordos basin. However, there still are $75 \%$ gas samples from Ordos basin sharing a normal distributing feature in carbon isotope $\left(\delta^{13} \mathrm{C}_{1}<\delta^{13} \mathrm{C}_{2}\right)$. About $25 \%$ gas samples from Ordos basin presents reversal between $\delta^{13} \mathrm{C}_{1}$ and $\delta^{13} \mathrm{C}_{2}\left(\delta^{13} \mathrm{C}_{1}>\delta^{13} \mathrm{C}_{2}\right.$, below the line of $\left.\delta^{13} \mathrm{C}_{1}=\delta^{13} \mathrm{C}_{2}\right)$.
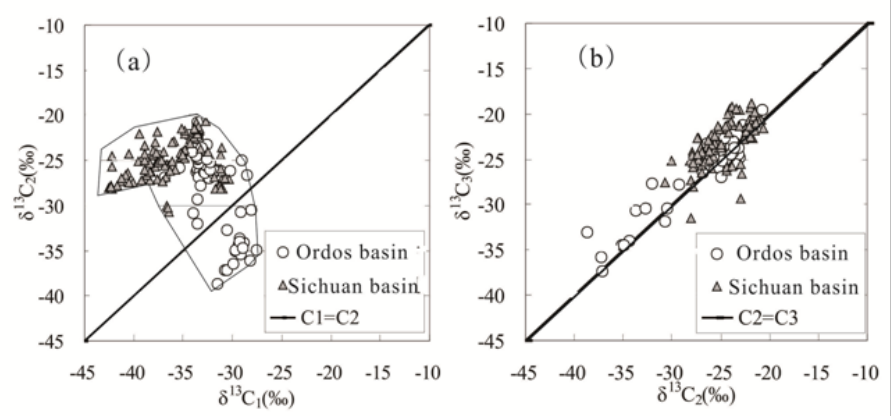

Figure 3 The carbon isotope relationships among of different hydrocarbon components.

The carbon isotope relationship between $\delta^{13} \mathrm{C}_{2}$ and $\delta^{13} \mathrm{C}_{3}$ is relatively complex (Figure $3 \mathrm{~b}$ ). All the samples are near the line of $\delta^{13} \mathrm{C}_{2}=\delta^{13} \mathrm{C}_{3}$. The samples from Sichuan basin is in a relatively narrow range along the line of $\delta^{13} \mathrm{C}_{2}=\delta^{13} \mathrm{C}_{3}$. Only a little samples (about $15 \%$ ) from Sichuan basin are below the line of $\delta^{13} \mathrm{C}_{2}=\delta^{13} \mathrm{C}_{3}$, which means a reversal between $\delta^{13} \mathrm{C}_{2}$ and $\delta^{13} \mathrm{C}_{3}$. The gas samples from Ordos basin is in a relatively wide range along the line of $\delta^{13} \mathrm{C}_{2}=\delta^{13} \mathrm{C}_{3} .30 \%$ gas samples from Ordos basin share reversal between $\delta^{13} \mathrm{C}_{2}$ and $\delta^{13} \mathrm{C}_{3}$. 


\section{The relationship between the carbon isotope series of gas and the maturity of source rock}

Hao et al. ${ }^{7}$ divided shale gas into following 4 types according to their carbon isotopic series. Type 1: normal series of carbon isotope with ${ }^{13} \mathrm{C}_{1}<\delta^{13} \mathrm{C}_{2}<\delta^{13} \mathrm{C}_{3}$, type 2: partial reversal with $\delta^{13} \mathrm{C}_{1}<\delta^{13} \mathrm{C}_{2}$ $>\delta^{13} \mathrm{C}_{3}$, type 3: partial reversal with $\delta^{13} \mathrm{C}_{1}>\delta^{13} \mathrm{C}_{2}<\delta^{13} \mathrm{C}_{3}$ and type 4: complete reversal with $\delta^{13} \mathrm{C}_{1}>\delta^{13} \mathrm{C}_{2}>\delta^{13} \mathrm{C}_{3}$. They further proposed that the distribution of above type shale gases was closely relative with the maturity of shale. Here, their thought is borrowed to inquire whether similar feature exists between the distribution of coal measure tight gas with different type of carbon isotope series and the maturity of in-situ source rock. The distributions of different type of coal measure tight gas from Sichuan and Ordos basin are presented in Figure 4, Figure 5, respectively.

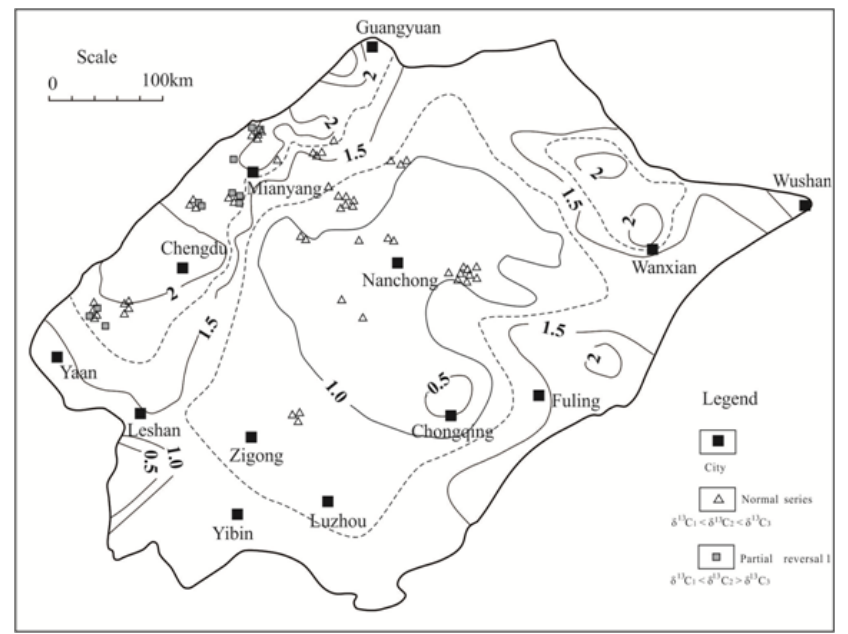

Figure 4 The distributions of gas with different carbon isotopic series and from Xujiahe group, Sichuan basin.

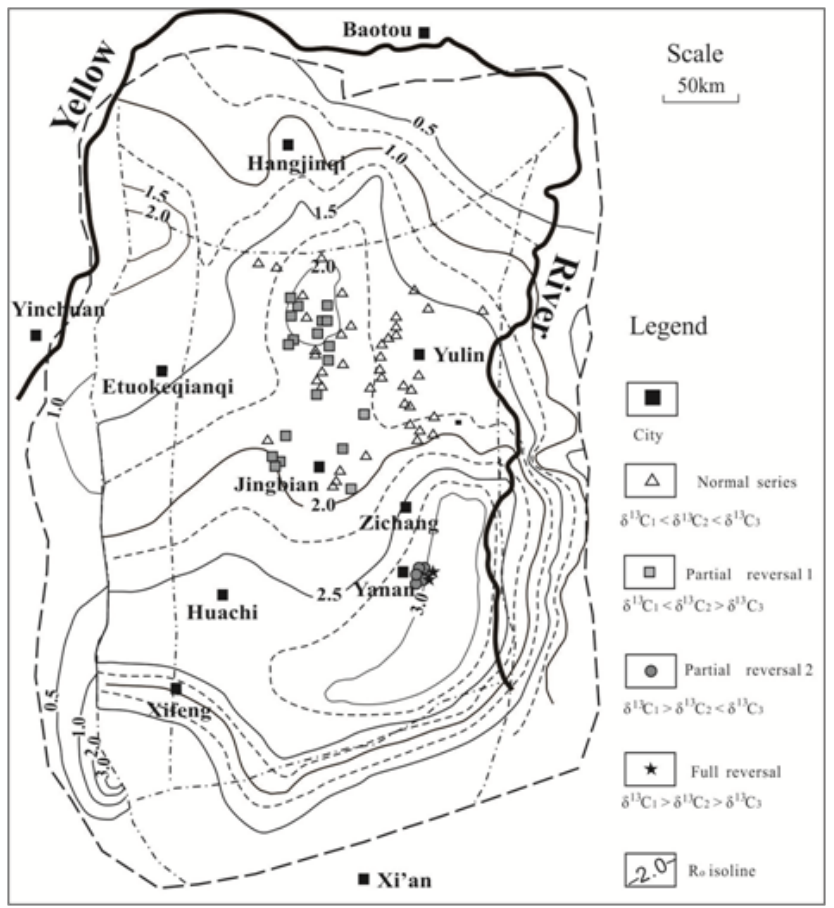

Figure $\mathbf{5}$ The distributions of gas from Upper Paleozoic, Ordos basin and with different carbon isotopic series.
The maturity of source rock developed in Xujiahe group, Sichuan basin is relatively low $\left(\mathrm{R}_{0}=0.5 \sim 2.0 \%\right.$, Figure 4$)$. Only type 1 and type 2 gases were found. Only type 1 gas was found in the area with the maturity of source rock less than $1.75 \% \mathrm{R}$. Both type 1 and 2 gas were found in the area where the maturity of source rock is in the range of $\mathrm{R}_{\mathrm{o}}=1.75 \sim 2.0 \%$; the maturity of source rock developed in Upper Paleozoic, Ordos basin is relatively high $\left(\mathrm{R}_{0}=1.0 \sim 3.2 \%\right.$, Figure 5). All the four type of gases were found. Similar as the distributions of different type gases found in Xujiahe group of Sichuan basin, type 1 gas distribute in area with the maturity of source rock less than 1.75 $\% \mathrm{R}_{\mathrm{o}}$ in Upper Paleozoic of Ordos basin. Both type 1 and 2 gases were found in the area where the maturity of source rock is in the range of $\mathrm{R}_{\mathrm{o}}=1.75 \sim 2.0 \%$. Type 3 gas was found in the area with $\mathrm{R}_{0}=2.0 \sim 3.0 \%$. Type 4 gas was found in the area with $\mathrm{R}_{\mathrm{o}}$ more than $3.0 \%$. It is difficult to determine the boundary line of the maturity area where the type 1 and 2 gases distribute for no gas found in the area with maturity of source rock ranged from $2.0 \mathrm{R}_{\mathrm{o}} \%$ to $2.75 \mathrm{R}_{\mathrm{o}} \%$ in Ordos basin at present. Nevertheless, the area of different type gas distribution is clear. Type 1 gas with normal carbon isotopic series is found in the area with $\mathrm{R}_{0}<1.75 \%$. The gas with partial reversal of carbon isotopic series occurs in the area with $\mathrm{R}_{0}=1.75 \sim 3.0 \%$. Type 4 gas with complete reversal of carbon isotopic series is in the area with $\mathrm{R}_{0}>3.0 \%$.

\section{The relationship between wetness of gas and the maturity of source rock}

Although the reservoir of coal measure tight gas is close to its source rock, it experiences a short distance migration. There should be some difference in gas field formation between shale gas and coal measure tight gas. However, coal measure tight gas shares similar feature in carbon isotopic evolution as shale gas that carbon isotopic series presents successively normal series, partial reversal and complete reversal distribution with decreasing maturity of source rock. The relationship between wetness of coal derived tight gas from Sichuan and Ordos basin and the maturity of source rock is presented Figure 6. It is clear that there is close relationship between the wetness of coal measure tight gas and the maturity of source rock. This indicates that the coal measure tight gas come from in-situ source rock and have no experience long distance migration. Hence, the isotopic fractionation of coal measure tight gas is weak during its migration or gas filed formation ${ }^{16}$ and the geochemistry of coal measure tight gas could mirror its generation mechanism.

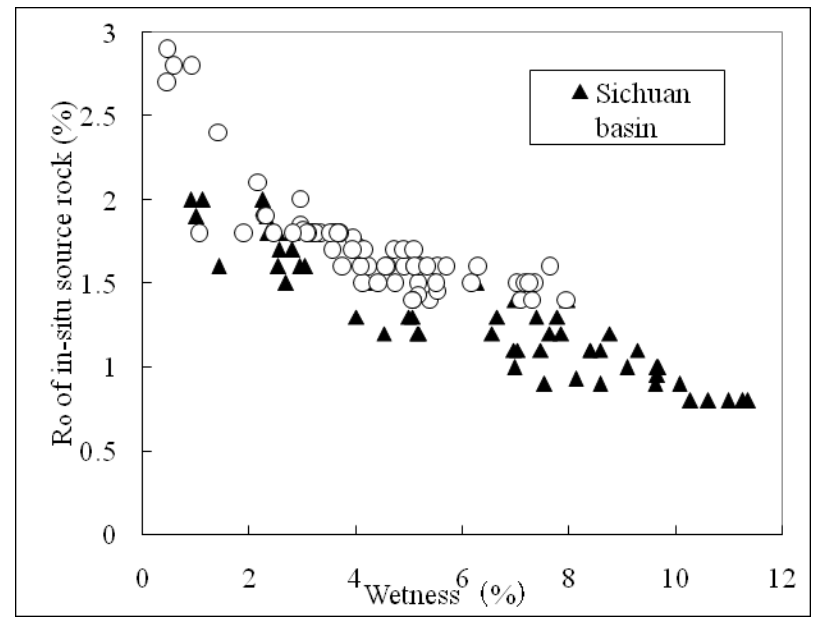

Figure 6 The relationship between wetness of gas and the maturity of in-situ source rock. 
Although the wetness $(2.5 \sim 5 \%)$ corresponding to $\delta^{13} \mathrm{C}_{2}$ rollover of coal measure tight gas from Ordos and Sichuan basin is different, but it is more than that of shale gas from Barnett (6\%, Figure 7). This is easy to understand because the marine OM from Barnett is oil prone and would generate gas with high wetness during its thermal evolution process comparing with that of coal. The wetness $(5 \%)$ corresponding to $\delta^{13} \mathrm{C}_{2}$ rollover of coal measure tight gas from Ordos basin is more than that $(2.5 \%)$ of gas from Sichuan basin. This is contributed to deposition of limestone or marlstone of Benxi and Taiyuan groups under coal bearing formation of Ordos basin (Figure 1). The oil prone source rock deposited transitional facies could generate gas with relatively high wetness during thermal evolution. The oil type gas with the relatively high content of heavy gas migrates into tight sandstone and mixes with coal derived gas. ${ }^{17}$ Thus, the wetness corresponding to $\delta^{13} \mathrm{C}_{2}$ rollover of tight gas from Ordos basin (5\%) is close to that of wetness value of shale gas $(6 \%)$ from Barnett and higher than that of gas from Sichuan basin. Nevertheless, the maturity corresponding to $\delta^{13} \mathrm{C}_{2}$ rollover for the gas from both Ordos basin and Sichuan basin is in same range of $1.5 \sim 1.7 \% \mathrm{R}_{0}$. This maturity range is slightly higher than that of $1.3 \sim 1.5 \% \mathrm{R}_{\mathrm{o}}$ for shale gas proposed by Hao et al. ${ }^{7}$

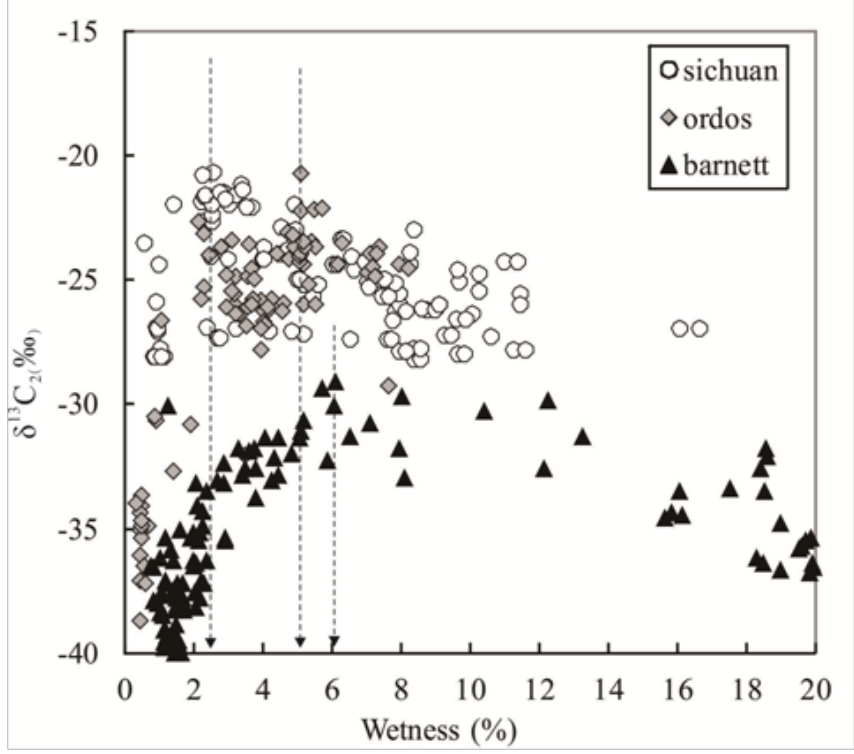

Figure 7 The comparison of wetness corresponding to $\delta^{13} C_{2}$ rollover for coal measure tight gas and shale gas.

This maturity range of $1.5 \sim 1.7 \% \mathrm{R}_{\mathrm{o}}$ is just in the stage of oil cracking. Although the coal is gas prone during its thermal evolution, but some oil could be generated. This is proved by the oil inclusion existed in tight sandstone of Ordos basin and cluster of bitumen with fluorescence. ${ }^{18}$ The oil remained in coal would crack and generate some gas with high content of heavy component and negative carbon isotope comparing to the primary gas generated by coal. The mixing between the primary and cracking gas would cause the carbon isotopic rollover of heavy gas generated by coal. Banett shale deposited in marine facies is oil prone. ${ }^{5}$ It would generate more oil during its thermal evolution process than coal. Thus, the amount of secondary cracking gas from shale will be more than that from coal. Meanwhile, the amount of primary gas from coal with relatively high dryness is more than that generated by type I and II source rock at a same maturity for its gas prone feature. There must be have a high cracking degree of oil generated by coal to match the $\delta^{13} \mathrm{C}_{2}$ rollover of coal derived gas. So, the maturity corresponding to $\delta^{13} \mathrm{C}_{2}$ rollover $\left(\mathrm{R}_{\mathrm{o}}=1.5 \sim 1.7 \%\right)$ of coal derived gas is higher than that of shale gas $\left(\mathrm{R}_{\mathrm{o}}=1.3 \sim 1.5 \%\right)$ proposed by Hao et al. ${ }^{7}$

\section{Preliminary study for mechanism of carbon isotopic rollover and reversal}

As mentioned in introduction, the view about isotopic reversal genesis of shale gases generated in over maturity stage in recent years could be induced into following aspects:

a. mixing between primary gas and cracking gas

b. Redox reaction between water and methane. The two reasons to cause the abnormal characteristic of isotopic at over maturity stay in theory and have no positive experimental proofs to support these explanation at present.

Gao et al. ${ }^{19}$ proved that mixing between primary gas from kerogen and secondary gas by remained hydrocarbons cracking could not produce isotope reversal, but just isotope rollover in shale gas observed in laboratory pyrolysis experiments conducted at hydro condition in closed system. In this study, a kerogen sample from lacustrine facies source rock $\left(\mathrm{R}_{\mathrm{o}}=0.6 \%\right.$ and $\mathrm{HI}=788 \mathrm{mg} / \mathrm{g}$.TOC) was selected to simulate hydrocarbon generation in gold tube system. This is a typical experiment to prove whether mixing between primary gas and the cracking gas could cause the carbon isotopic rollover of heavy gas and reversal of hydrocarbon gas for its close feature. The carbon isotopic evolution of methane, ethane and propane with increasing experimental temperature and Easy $\mathrm{R}_{\mathrm{o}}$ of sample residues is presented in Figure 8. Surely, there is a depletion of $\delta^{13} \mathrm{C}_{2}$ and $\delta^{13} \mathrm{C}_{3}$ in $400 \sim 450^{\circ} \mathrm{C}$. The corresponding Easy $\mathrm{R}_{\mathrm{o}}$ to the turning point of $\delta^{13} \mathrm{C}_{2}$ and $\delta^{13} \mathrm{C}_{3}$ rollover is about $1.26 \% \mathrm{R}_{0}$. The maturity of $1.26 \% \mathrm{R}_{0}$ is just end of oil window and the start of oil cracking. Nevertheless, the carbon isotope of hydrocarbon hold a normal feature of ${ }^{13} \mathrm{C}_{1}<\delta^{13} \mathrm{C}_{2}$ $<\delta^{13} \mathrm{C}_{3}$ in all experimental temperature. The result of the experiment indicates that the mixing between primary gas and the cracking gas could not make the isotopic reversal of hydrocarbon gas. It just only causes the isotopic rollover of heavy gases. The Easy $\mathrm{R}_{\mathrm{o}}$ of $1.26 \%$ corresponding to $\delta^{13} \mathrm{C}_{2}$ and $\delta^{13} \mathrm{C}_{3}$ rollover from above experiment is lower than $1.3 \sim 1.5 \% \mathrm{R}_{0}$ corresponding to $\delta^{13} \mathrm{C}_{2}$ and $\delta^{13} \mathrm{C}_{3}$ rollover of shale gas proposed by Hao et al. ${ }^{7}$ This is contributed to the pyrolysis experiment is conducted in compeltely close system and no oil expelled during experiment. Of course, the isotopic full reversal of coal derived gas caused by mixing between primary gas and the cracking gas is more unlikely for less oil and high dryness of primary gas generated by coal comparing with oil prone OM during its thermal evolution.

The second view about isotopic reversal of shale gas that cause by the redox reaction of methane and further reaction to form isotopically light ethane is just a theoretical assumption or model. It needs to be proved by more experiments. The second part reaction of this assumption is similar with Fischer-Tropsch (FT) Synthesis between carbon dioxide and hydrogen. Although the FT synthesis between $\mathrm{H}_{2}$ and $\mathrm{CO}_{2}$ could generate hydrocarbon gas with isotopic reversal, ${ }^{20}$ this reaction conducted in lab and with transition metal as catalyst generally. However, whether the amount of transition metal existed in source rock is enough or not to make the happening of FT synthesis between $\mathrm{H}_{2}$ and $\mathrm{CO}_{2}$ could is doubtable. Even if the synthesis between $\mathrm{H}_{2}$ and $\mathrm{CO}_{2}$ could happen in source rock, the reactants of $\mathrm{H}_{2}$ and $\mathrm{CO}_{2}$ could not come from the redox reaction of methane, but come 
from the thermal evolution process of source rock. The geological temperature range of $250-300^{\circ} \mathrm{C}$ or maturity of $5.0 \% \mathrm{R}_{\mathrm{o}}$ at which the redox reaction of methane happens is so high that the ethane generated by FT synthesis would crack at once. Thus, the carbon isotopic series of hydrocarbon gas could not share the reversal characteristic for the cracking of heavy gas. $\mathrm{CO}_{2}$ generation occurs in all process of $\mathrm{OM}$ evolution. ${ }^{18}$ Moreover, $\mathrm{H}_{2}$ could generate at over maturity stage of $\mathrm{OM}$ by condensation of aromatic rings to form graphite. However, bulk $\mathrm{H}_{2}$ generates by condensation of aromatic rings at the maturity more than $3.0 \% \mathrm{R}_{0}{ }^{21}$ Thus, FT synthesis between $\mathrm{H}_{2}$ and $\mathrm{CO}_{2}$ in source rock system should happen above $3.0 \% \mathrm{R}_{0}$. Nevertheless, whether the hydrocarbon gas generated by FT synthesis between $\mathrm{H}_{2}$ and $\mathrm{CO}_{2}$ at the maturity stage more than $3.0 \% \mathrm{R}$ would happen or not in source rock system needs more experimental data to support.

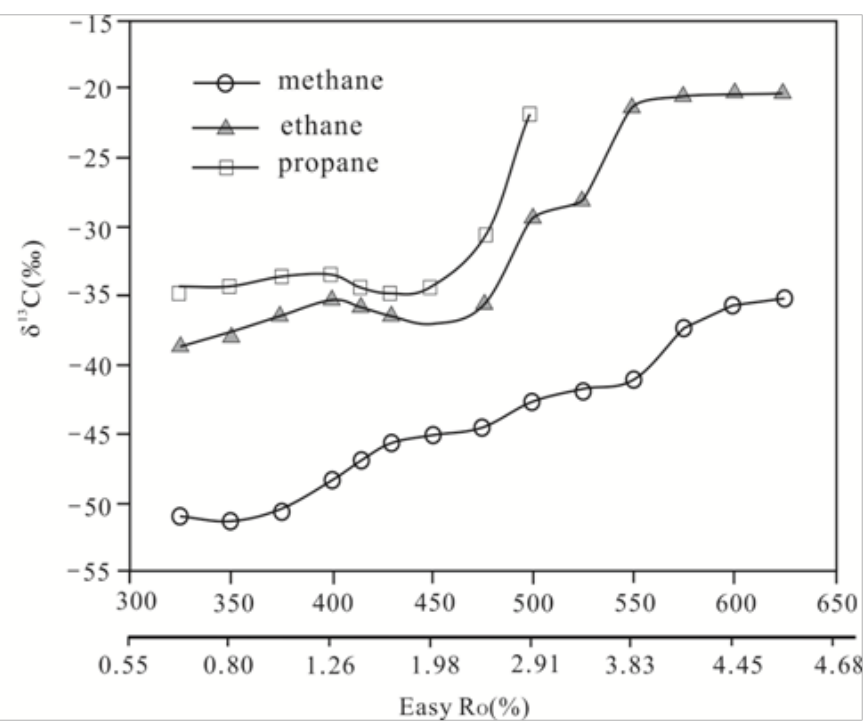

Figure 8 The carbon isotope of hydrocarbon generated by oil prone organic matter in pyrolysis experiment.

The geochemistry data of natural gas indicates that the isotopic reversal is not a peculiar feature for shale gas. Coal measure tight gas also shares the feature of the carbon isotopic reversal at the maturity stage more than $3.0 \% \mathrm{R}_{0}$. Yao et al. ${ }^{22}$ proposed that there is no aliphatic chains with more than two carbon atom in the chemical structure of coal with maturity of $2.8 \% \mathrm{R}_{\mathrm{o}}$ by measurement using fourier transform infrared spectroscopy (FTIR) for geological samples and the residues of coal pyrolysis. Mi et al. ${ }^{23}$ presented a similar result that only methyl as side chain could be measured by ${ }^{13} \mathrm{C}$ nuclear magnetic resonance in the chemical structure of coal with maturity more than $3.0 \% \mathrm{R}_{0}$. The carbon isotopic reversal must have relationship with demethylation. Fusetti et al. ${ }^{24}$ Studied the demethylation contribution to gas generation from $\mathrm{OM}$ and extensively existed at over maturity level by trimethylbenzene pyrolysis experiment in gold tube. Their experimental result indicated that there is some heavy gas produced beside methane. Unfortunately, carbon isotope of ethane did not be measured in their experiment. Nevertheless, the fractionation mechanism of carbon isotope during heavy gas generation by demethylation could be deducted according to the relative theory. It is well know that inorganic hydrocarbon gas has a feature of isotopic reversal..$^{25-27}$ The heavy gas of inorganic origin is suggested by via conjunction of methane. ${ }^{25,27,28}$ The isotope fractionation during of heavy gas generation is well recognized to be the reason of isotope reversal for inorganic hydrocarbon gas. This thought could be borrowed to interpret the carbon isotopic reversal of natural gas generated by demethylation, which extensively exists in $\mathrm{OM}$ at over maturity stage.

The measurement results about chemical structure indicate that only methyl as the side chains linked on aromatic rings for the coal samples with maturity more than $3.0 \% \mathrm{R}_{0}{ }^{23}$ In theory, the unique component of gas generated via demethylation at the maturity more than $3.0 \% \mathrm{R}$ should just be methane. However, there is some heavy gas occurred both in the natural gas found in shale gas or coal measure tight gas with source rock maturity more than $3.0 \% \mathrm{R}$ and in the gases produced in lab by trimethylbenzene cracking. The heavy gas must be generated by reciprocally conjunction of free $\mathrm{CH}_{3}^{+}$, which forms via cleavage of methyl linked on aromatic rings. The free $\mathrm{CH}_{3}^{+}$would links with $\mathrm{H}^{+}$and forms $\mathrm{CH}_{4}$. Some $\mathrm{CH}_{3}{ }^{+}$would connect reciprocally and form heavy gas. There are two kinds of carbon isotopic components in free $\mathrm{CH}_{3}^{+},{ }^{12} \mathrm{CH}_{3}{ }^{+}$and ${ }^{13} \mathrm{CH}_{3}{ }^{+}{ }^{12} \mathrm{CH}_{3}^{+}$bears a higher kinetic energy than ${ }^{13} \mathrm{CH}_{3}^{+}$in a same energy system for its relatively light mass during above linkage. Thus, a relative higher conjunction probability to form heavy gas among ${ }^{12} \mathrm{CH}_{3}^{+}$exists than that between ${ }^{12} \mathrm{CH}_{3}^{+}$and ${ }^{13} \mathrm{CH}_{3}^{+}$, or than that between ${ }^{13} \mathrm{CH}_{3}^{+}$and ${ }^{13} \mathrm{CH}_{3}^{+}$. So, heavy gas generated by free $\mathrm{CH}_{3}{ }^{+}$conjunction has a depleted carbon isotope component (Appendix 1). Thus, the isotopic fractionation during the process of heavy gases formation by linkage of methyl from demethylation is one of capital factors of carbon isotopic reversal. ${ }^{29-32}$

\section{Conclusion}

The statistical analysis on geochemistry data of gas from Xujiahe, Sichuan Basin and Upper Paleozoic reservoirs, Ordos Basin, China indicates that coal measure tight gas share a similar evolution feature in carbon isotope as shale gas. The carbon isotope of heavy gas would present a rollover with the decreasing wetness of coal measure tight gas. The corresponding range of gas wetness is about $2.5 \% \sim 5 \%$ at which the carbon isotope of ethane begin to rollover, which is less than that of shale gas $(6 \%)$. The carbon isotope series of coal measure tight sandstone gas would present successively positive sequence, partial reverse and full reversal with increasing maturity of in-situ source rock. The close relationship between the wetness and the maturity of source rock indicated that coal measure tight gas is the in-situ gas. Moreover, the distribution of coal measure tight gas with different carbon isotopic series is relative with the maturity of source rock. The maturity ranges corresponding to of coal measure tight sandstone gas with the normal sequence, partial reversal and full reversal of carbon isotope are $\mathrm{R}_{0}<1.75 \%, \mathrm{R}_{0}=1.75 \sim 3.0 \%$ and $\mathrm{R}_{0}>3.0 \%$, respectively. The authors suggest that the mixing between the primary gas and the cracking gas just only cause the carbon isotopic rollover of heavy gases, but not make the complete reversal in carbon isotope of hydrocarbon gas. A conclusion is proposed that the carbon isotopic reversal of gas is contributed to demethylation happening at the maturity above $3.0 \% \mathrm{R}$ of source rock. The carbon isotopic fractionation during the process of heavy gases formation by linkage of methyl is one of real factors caused the full reverse of carbon isotope for coal measure gas.

\section{Acknowledgments}

This research supported by Projects supported by the National Natural Science Foundation of China (Grant No, 41673047) and the Major Program of the National Oil and Gas Foundation of China (Grant No, 2016ZX05007-001). 


\section{Conflict of interest}

The author declares no conflict of interest.

\section{References}

1. Tissot BP, Durand B, Espitalie J. Influence of the nature and diagenesis of organic matter in formation of petroleum. AAPG bulletin. $1974 ; 58(3): 499-506$

2. James AT. Correlation of natural gas by use of carbon isotopic distribution between hydrocarbon components. AAPG Bulletin. 1983;67(7):11761191.

3. Jenden PD, KD Newell, IR Kaplan, et al. Composition and Stableisotope Geochemistry of natural gases from Kansas, Midcontinent, USA Chemical Geology. 1988;71(1-3):117-147.

4. Prinzhofer A, Huc AY. Genetic and post-genetic molecular and isotopic fractionations in natural gases. Chemical Geology. 1995;126(3-4):281290 .

5. Rodriguez ND, Philp RP. Geochemical characterization of gases from the Mississippian Barnett Shale, Fort Worth Basin, Texas. AAPG Bulletin. 2010. 94(11):1641-1656.

6. Zumberge J, Ferworn KJ, Brown S. Isotopic reversal ('rollover') in shale gases produced from the Mississippian Barnett and Fayetteville formations. Marine and Petroleum Geology. 2012;31(1):43-52.

7. Hao F, Zou HY. Cause of shale gas geochemical anomalies and mechanisms for gas enrichment and depletion in high-maturity shales. Marine and Petroleum Geology. 2013;44:1-12.

8. Tilley B, Muehlenbachs K. Isotope reversals and universal stages and trends of gas maturation in sealed, self-contained petroleum systems. Chemical Geology. 2013;339:194-204.

9. Wu W, Fang CC, Dong DZ, et al. Shale gas geochemical anomalies and gas source identification. Acta petrolei sinica. 2015;36(11):1332-1339.

10. Xia XY, Chen J, Braun R, et al. Isotopic reversals with respect to maturity trends due to mixing of primary and secondary products in source rocks. Chemical Geology. 2013;339:205-212.

11. Burruss RC, Laughrey CD. Carbon and hydrogen isotopic reversals in deep basin gas:evidence for limits to the stability of hydrocarbons Organic Geochemistry. 2010;41(12):1285-1296.

12. Dai JX, Ni YY, Huang SP, et al. Origins of secondary negative carbon isotopic series in natural gas. Natural Gas Geoscience. 2016;27(1):1-7.

13. Feng Ziqi, Liu Dan, Huang Shipeng, et al. Geochemical characteristics and genesis of natural gas in the Yan'an gas field, Ordos Basin, China Organic Geochemistry. 2016;102:67-76.

14. Zhang SC, Mi JK, Liu LH, et al. Geological features and formation of coal formed tight sandstone gas pools in China:Cases from Upper Paleozoic gas pools, Ordos Basin and Xujiahe Formation gas pools, Sichuan Basin Petroleum Exploration and Development. 2009;(3):320-330.

15. Dai JX, Song Y, Zhang HF. The main control factors for giant gas fields formation in China. Science in China Serise (D). 1996. 26(6):1-8.

16. Hu GY, Li J, Shan XQ, et al. The origin of natural gas and the hydrocarbon charging history of the Yulin gas field in the Ordos Basin, China. International Journal of Coal Geology. 2010;81(4):381-391.
17. Xia XY. Hydrocarbon generation from carbonate source rocks and origin of Changqing gas field. China: Petroleum Industry Press; 2000.

18. Mi JK, Xiao XM, Liu DH. Determination of paleo-pressure for a natural gas pool formation based on PVT characteristics of fluid inclusions in reservoir rocks. Science in China Serise (D). 2004. 47(6):507-513.

19. Gao L, Schimmelmann A, Tang YC, et al. Isotope rollover in shale gas observed in laboratory pyrolysis experiments:Insight to the role of water in thermogenesis of mature gas. Organic Geochemistry. 2014;68:95-106.

20. Zhang SC, Mi JK, He K. Synthesis of hydrocarbon gases from four different carbon sources and hydrogen gas using a gold-tube system by Fischer-Tropsch method. Chemical Geology. 2013;349-350:27-35.

21. Chen JM, Li XQ, Qi S, et al. Study on relationship between evolution of coal chemical structure and gas generation from coal. Natural Gas Geoscience. 2017;28(6):863-872.

22. Yao SP, Zhang K, Jiao K, et al. Evolution of coal structures:FTIR analyses of experimental simulations and naturally matured coals in the Ordos Basin, China. Energy Exploration \& Exploitation. 2011;29(1):1-19.

23. Mi JK, Zhang SC, Jianping Chen JP, et al. Upper thermal maturity limit for gas generation from humic coal. International Journal of Coal Geology. 2015;152(Part A):123-131.

24. Fusetti L, Behar F, Bounaceur R, et al. New insights into secondary gas generation from the thermal cracking of oil:Methylated mono-aromatics. A kinetic approach using 1,2,4-trimethylbenzene. Part III:An empirical kinetic model. Organic Geochemistry. 2010;41(5):431-436.

25. Horita J, Berndt ME. Abiogenic methane formation and isotopic fractionation under hydrothermal conditions. Science. 1999;285 (5430):1055-1057

26. Dai JX, Yang SF, Chen HL, et al. Geochemistry and occurrence of inorganic gas accumulations in Chinese sedimentary basins. Organic Geochemistry. 2005;36(12):1664-1688.

27. SherwoodLollar B, Lacrampe-Couloume G, Voglesonger K, et al. Isotopic signatures of $\mathrm{CH}_{4}$ and higher hydrocarbon gases from Precambrian Shield sites:A model for abiogenic polymerization of hydrocarbons. Geochimica et Cosmochimica Acta. 2008;72(19):47784795 .

28. Hu G, Quyang Z, Wang X, et al. Carbon isotopic fractionation in the process of Fisher-Tropsch reaction in primitive solar nebula. Science in China (Series D). 1998. 41(2):202-207.

29. Dai J X. Major developments of coal-formed gas exploration in the last 30 years in China. Petroleum Exploration and Development. 2009;36(3):264-279.

30. McCollom TM, Sherwood Lollar BS, Lacrampe-Couloume G, et al. The influence of carbon source on abiotic organic synthesis and carbon isotope fractionation under hydrothermal conditions. Geochimica et Cosmochimica Acta. 2010;74(9):2717-2740.

31. Sherwood Lollar B, Lacrampe-Couloume G, Slater GF, et al Unravelling abiogenic and biogenic sources of methane in the Earth's deep subsurface. Chemical Geology. 2006;226(3-4):328-339.

32. Tilley B, McLellan S, Hiebert S, et al. Gas isotope reversals in fractured gas reservoirs of the western Canadian Foothills:Mature shale gases in disguise. AAPG Bulletin. 2011;95(8):1399-1422. 